УДК 339.542 .2

ББК 65.9(2Рoc)-5

ОСОБЕННОСТИ ПРОМЫШЛЕННОЙ ПОЛИТИКИ РОССИИ В КОНТЕКСТЕ СТРУКТУРНЫХ ИЗМЕНЕНИЙ*

\author{
Д. Р. ГАЛОЯН \\ доктор экономических наук, доцент, заведующий кафедрой международных \\ экономических отношений \\ Армянский государственный экономический университет \\ Ереван, Республика Армения \\ В. В. КАРАПЕТЯН \\ соискатель кафедры международных экономических отношений \\ Армянский государственный экономический университет \\ Ереван, Республика Армения \\ О. М. МАЗУРЕНКО \\ аспирант кафедры «Экономика и право» \\ Белорусский национальный технический университет \\ Минск, Республика Беларусь
}

Промышленная политика России в 1990-х годах была направлена на предотвращение негативных структурных изменений в экономике страны, а также на компенсацию потерь от неконкурентоспособных отечественных производителей. Однако в конще 2014 года рост геополитических рисков заставил изменить подходы индустриальной политики. Этот период характеризуется сокращением инвестиций и резкой девальвацией. В результате в настоящее время очень важна настоятельная необходимость радикальных изменений в подходах промылиенной политики, которые охватьвают разнородные меры иной функциональной политики и подразумевают их влияние на конкретные сектора экономики.

Ключевые слова: промышленная политика, приоритеты, структура экономики, инновационная система, конкурентоспособность.

\title{
PECULIARITIES OF INDUSTRIAL POLICY OF RUSSIA IN THE CONTEXT OF STRUCTURAL CHANGES*
}

\section{R. GALOYAN}

Doctor in Economics, Associate professor, Head of the Chair of international economic relations

Armenian State University of Economics

Yerevan, Republic of Armenia

V. V. KARAPETYAN

Applicant of the Chair of international economic relations

Armenian State University of Economics

Yerevan, Republic of Armenia

O. M. MAZURENKO

Postgraduate student of the Chair "Economics and Law"

Belarusian National Technical University

Minsk, Republic of Belarus

\footnotetext{
* Исследование выполнено при финансовой поддержке ГКН МОН РА и БРФФИ (Республика Беларусь) в рамках совместных научных программ НВ 16-03 и Г17АРМ001 соответственно

${ }^{*}$ This work was supported by the RA MES State Committee of Science and Belarusian Republican Foundation for Fundamental Research (Republic of Belarus) in the frames of the joint research projects SCS HB16-03 and BRFFR G17APM001 accordingly.
} 
Industrial policy of Russia in the 1990's was aimed at preventing negative structural changes in the country's economy, as well as compensation for losses from non-competitive domestic producers. However, by the end of 2014 the increase in geopolitical risks forced the industrial policy approaches to change. This period is characterized by a reduction in investment and a sharp devaluation. As a result, at present, the urgency of radical changes is high in industrial policy approaches that would group the heterogeneous measures of other functional policies and accentuate their impact on specific sectors of the economy.

Keywords: industrial policy, priorities, economic structure, innovation system, competitiveness.

\section{ВВЕДЕНИЕ}

С целью осуществления единой промышленной политики в рамках ЕАЭС, направленной на ускорение устойчивости промышленного развития государств-членов, нужно произвести глубокий анализ национальных политик индустриализации. Это позволит выделять секторальные проблемы и направить инвестиции и финансовые ресурсы в проблемные сектора стран [1].

Итак, промышленная политика России в 1990-х гг. была направлена на предотвращение негативных структурных изменений в экономике страны, а также на компенсацию убытков от неконкурентоспособных отечественных производителей [2]. Однако возрастание геополитических рисков в конце 2014 г. заставило изменить подходы промышленной политики. Этот период характеризуется сокращением инвестиций и резкой девальвацией. В результате этого в настоящее время актуальность коренного изменения подходов к проведению промышленной политики, которая бы сгруппировала разнородные меры других функциональных политик и акцентировала их влияние на конкретные сектора экономики, является очень высокой.

Общество и государство в России традиционно демонстрируют высокий спрос на промышленную политику. Несмотря на широко распространенное мнение российских экспертов об отрицательном последствии вмешательства государства в регулирование этой области, большое количество практических вопросов требует скоординированных и централизованных мер, принятие которых лежит исключительно в компетенции государственных органов. К таким мерам относятся: определение приоритетов при принятии решений о снижении (повышении) налоговой нагрузки или изменения таможенных сборов; согласование условий присоединения к внешнеэкономической системе; предоставление выборочной поддержки определенным секторам во время кризиса; выбор льготных областей инвестиций.

Внутренняя промышленная политика имеет потенциал преодоления различных экономических проблем и может гарантировать долгосрочный рост путем диверсификации экономики, замещения импорта, увеличения объема экспорта, развития исследований и использования российских научных разработок.

\section{РЕЗУЛЬТАТЫ И ИХ ОБСУЖДЕНИЕ}

Мировой опыт показывает, что требования к промышленной политике, ее инструментам и другим возможностям значительно меняются со временем. Адаптация к меняющимся условиям требует постоянного обзора предыдущих подходов к промышленной политике и реализации новых идей и решений. Крайне сложно передать успешный опыт и воспроизвести успехи других стран. 
Ретроспективные (ex post) оценки промышленной политики ценны не только для их способности определять необходимое направление политики, но также формулировать принципы для разработки, осуществления, мониторинга и обзора. Решающую роль в этой области играют методы формулирования и реализации политики наряду с качественным государственным управлением.

Широко признано, что центральным элементом промышленной политики является система отраслевых и технологических приоритетов, которая до сих пор не сформировалась в России каким-либо ясным и действенным образом. В то же время каждый новый раунд интереса к промышленной политике в России начинается с обсуждения приоритетов.

В разное время Россия предпринимала множество попыток осуществить промышленную политику. Из-за привлекательности этого инструмента как простого и эффективного механизма сотрудничества с обществом, перераспределения доходов и удовлетворения интересов экономических субъектов - такие попытки будут повторяться. Промышленная политика позволяет переформатировать традиционный комплекс мер по улучшению инвестиционного климата, оптимизировать государственное регулирование и объединить различные стратегии, направленные на достижение четких целей. Принимая во внимание различные формы российской промышленной политики, можно выделить некоторые закономерности и особенности.

Результаты промышленной политики России 2000-х гг. в основном показывают отсутствие корреляции между экономическими реалиями и целью, объявленной государством для более десяти лет, чтобы уменьшить роль сектора добычи сырья и поддерживающих перерабатывающие производства. Доля добывающих отраслей в процентах валовой добавленной стоимости демонстрирует сильные восходящие тенденции, тогда как доля перерабатывающей промышленности падает с 2002 года (рисунок 1). Конечно, важно помнить, что ускоренное развитие сырьевых отраслей было вызвано прежде всего ситуацией на внешнем рынке, а перерабатывающие отрасли ориентированны почти исключительно на внутренний спрос.

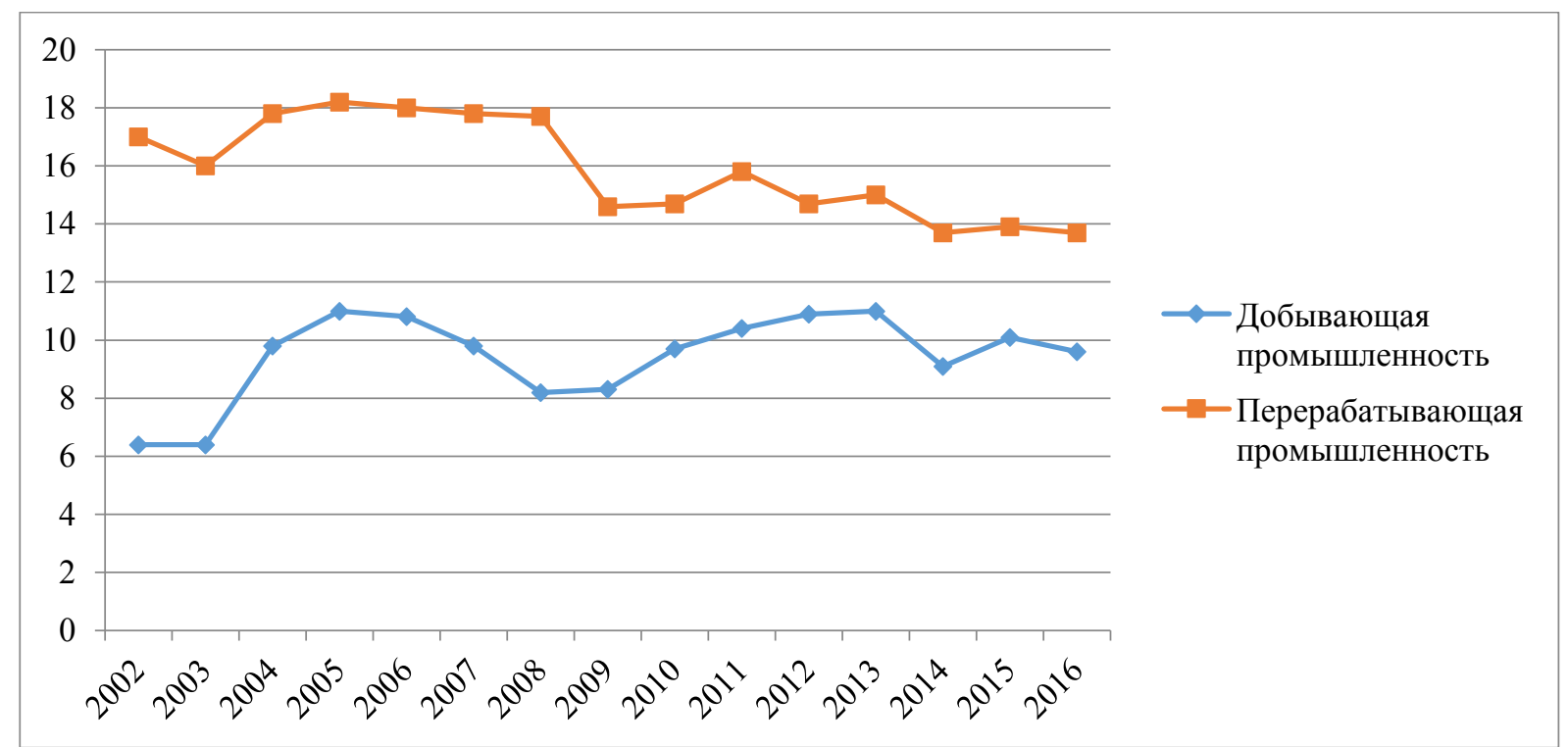

Рисунок 1 - Доля добывающей и перерабатывающей промышленности в ВВП России (\%) Источник: [3].

В последние годы увеличение доли инновационной продукции в совокупном выпуске не сопровождалось заметным ростом доли наукоемких или высокотехнологичных 
секторов экономики. Отсутствие каких-либо явных успехов в российской промышленной политике по сравнению с экономикой страны в целом ставит задачу поиска и изучения локальных достижений в некоторых секторах и отраслях промышленности. В качестве примеров промышленной политики мы выбрали передовые производственные технологии.

Эта отрасль способна достичь положительных результатов, но она рассматривается не с точки зрения поддержки занятости, а как мост к экономике будущего, которая открывает перспективы для использования передовых исследований и разработок. Технологическая промышленная политика включает в себя комплекс мер по формированию нового высокотехнологичного сектора значительного размера для национальной экономики и конкурентоспособности в глобальном масштабе. Ключом к этому является создание необходимой инфраструктуры (в том числе финансовой), гарантирующей продвинутые НИОКР и стремление увеличить выпуск высоких технологий. Все странылидеры мирового хозяйства уделяют особое внимание инновационной составляющей экономического роста, которая является необходимым фактором развития страны. Однако, в последние годы в России не наблюдается рост затрат на НИОКР. Динамика показателя расходов на исследования и разработки в процентах от ВВП России представлена в таблице 1.

Таблица 1 - Внутренние затраты на исследования и разработки, в процентах от валового внутреннего продукта в целом по Российской Федерации в 2010-2016 гг.

\begin{tabular}{|l|l|l|l|l|l|l|l|}
\hline & $\mathbf{2 0 1 0}$ & $\mathbf{2 0 1 1}$ & $\mathbf{2 0 1 2}$ & $\mathbf{2 0 1 3}$ & $\mathbf{2 0 1 4}$ & $\mathbf{2 0 1 5}$ & $\mathbf{2 0 1 6}$ \\
\hline $\begin{array}{l}\text { Всего по Российской } \\
\text { Федерации, \% }\end{array}$ & 1,13 & 1,01 & 1,03 & 1,03 & 1,07 & 1,10 & 1,10 \\
\hline
\end{tabular}

Источник: [3]

Как видим в 2010-2016 гг. в России затраты на исследования и разработки в общем объеме ВВП снизились: если в 2010 году они составили 1,13\% ВВП, то в 2016 году упали до $1,10 \%$. В исследуемыц период самый низкий показатель был зафиксирован на уровне 1,01\% в 2011 году.

Мировые расходы на НИОКР в последние годы достигли рекордных 1,7 триллионов долларов, из которых 80 \% приходится на 10 развитых стран. В первой пятерке лудеров - Южная Корея, Израиль, Япония, Финляндия, Швеция, а Россия идет вровень с Испанией, Португалией, Малайзией и Италией. Но в большинстве стран основное бремя расходов на новые разработки несет корпоративный сектор. Например, в Израиле на долю бизнеса приходится порядка 85 \% НИОКР, в США - 70 \%, в России - $60 \%$, Сингапуре - 59 \%, Австралии - $56 \%$, Индии - всего $36 \%$. В Бразилии, судя по этим данным, за научные разработки отвечает исключительно государство [4]. Однако, российские компании предпочитают тратить большую сумму на закупки оборудования и техники, чем на полезные для них исследования.

Развитие технологического сектора в стране можно также представить по динамике показателя объемов и доли высокотехнологичных отраслей. Удельный вес инновационных товаров в общем объеме отгруженных товаров в целом по Роосии по видам экономической деятельности по данным 2016 г. составила $18.2 \%$, то есть наблюдается увелечение по сравнению с показателями 2012 г. (таблица 2).

С одной стороны, приведенные данные не позволяют нам однозначно оценить опыт России в области промышленной политики, а с другой стороны, они показывают признаки значительного прогресса в области высоких технологий, так как положительные результаты, по нашему мнению, явно опережают негативные. 
Таблица 2 - Объем инновационных товаров по Российской Федерации по видам экономической деятельности

\begin{tabular}{|l|c|c|c|c|c|}
\hline & $\mathbf{2 0 1 2}$ & $\mathbf{2 0 1 3}$ & $\mathbf{2 0 1 4}$ & $\mathbf{2 0 1 5}$ & $\mathbf{2 0 1 6}$ \\
\hline $\begin{array}{l}\text { Высокотехнологичные виды } \\
\text { экономической деятельности }\end{array}$ & $\mathbf{1 2 2 3 ~ 1 0 6 , 4}$ & $\mathbf{1 4 0 4} \mathbf{4 1 9 , 5}$ & $\mathbf{1 ~ 5 5 1 ~ 9 8 3 , 2}$ & $\mathbf{1 ~ 8 0 3 ~ 7 0 8 , 3}$ & $\mathbf{2 ~ 0 8 3 ~ 4 1 3 , 4}$ \\
\hline в процентах & $\mathbf{1 4 , 3}$ & $\mathbf{1 6 , 9}$ & $\mathbf{1 7 , 7}$ & $\mathbf{1 8 , 6}$ & $\mathbf{1 8 , 2}$ \\
\hline $\begin{array}{l}\text { производство } \\
\text { фармацевтической продукции }\end{array}$ & 195555,7 & 208611,2 & 212382,4 & 237041,2 & 297640,9 \\
\hline $\begin{array}{l}\text { производство офисного } \\
\text { оборудования и вычислитель- } \\
\text { ной техники }\end{array}$ & 46202,4 & 48389,3 & 45598,4 & 57377,5 & 59546,3 \\
\hline $\begin{array}{l}\text { производство электронных } \\
\text { компонентов, аппаратуры } \\
\text { для радио, телевидения и связи }\end{array}$ & 265555,0 & 281185,6 & 313132,2 & 323153,2 & 380201,5 \\
\hline $\begin{array}{l}\text { производство медицинских } \\
\text { изделий; средств измерений, } \\
\text { контроля,управления и испыта- } \\
\text { ний;оптических приборов, } \\
\text { фото- и кинооборудования;часов }\end{array}$ & 283468,2 & 303002,4 & 353151,8 & 458284,1 & 524 400,4 \\
\hline $\begin{array}{l}\text { производство летательных } \\
\text { аппаратов, включая космические }\end{array}$ & 432325,1 & 563231,1 & 627718,4 & 727852,3 & 821624,3 \\
\hline
\end{tabular}

Источник: [3]

Производство высокотехнологичной продукции представляет собой важный фактор конкурентоспособности страны [5]. Однако не только производство, но и спрос на эти товары на мировом рынке определяют роль и место данной страны в процессах, международного разделения труда. Для этой цели была рассчитана технологическая емкость экспорта России. По полученным данным Россия мало представлена на рынке продукции высоких технологий. По данным 2016 г. доля российского экспорта высокотехнологичной продукции в мировом экспорте высокотехнологичной продукции составила $0,2 \%$, а в общем экспорте $-0,08 \%$. В то же время доля экспорта высокотехнологичной продукции в общем экспорте РФ в 2016 г. составила 4,5\%.

Наибольший вес в мировом экспорте у России в группе «Реакторы ядерные, котлы, оборудование и механические устройства; их частях» $(0.4 \%)$, «инструменты и аппараты оптические, фотографические, кинематографические неэлектрических машин» $(0,3 \%)$. Самое незначительное участие России в мировом экспорте высокотехнологичной продукции наблюдается по таким группам, как летательные аппараты, космические аппараты, и их части, фармацевтическая продукция $(0,1 \%)$. Доля России невелика также в мировом импорте высокотехнологичных товаров. В России, помимо слабо развитого экспортного направления высокотехнологичного производства, наблюдается также относительно невысокий спрос внутренней экономики на высокотехнологичную импортную продукцию. Однако внешнеторговый баланс России в сфере высокотехнологичной продукции имеет пассивный характер, и в 2016 г. составил 58023 млн долларов. 


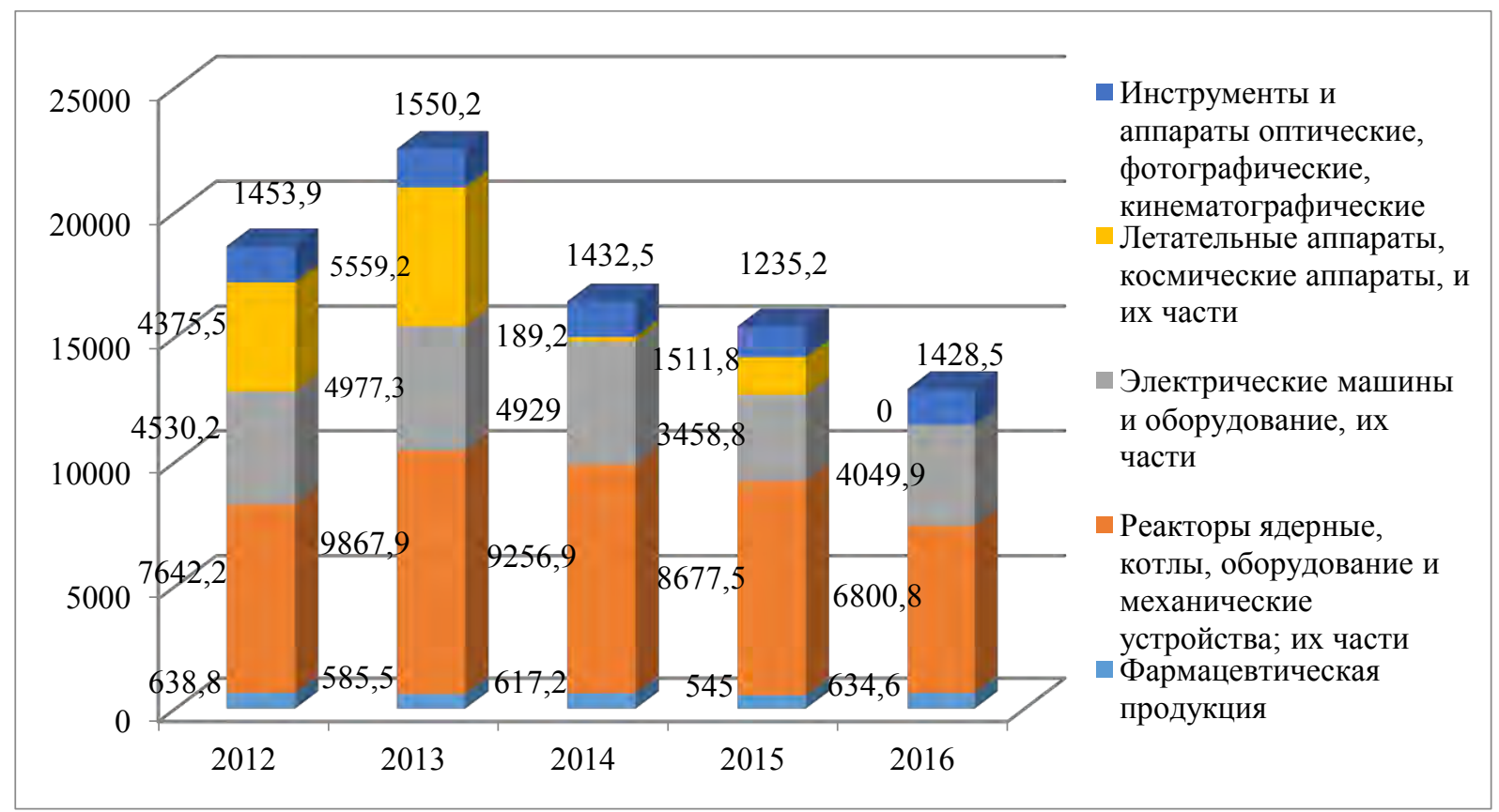

Рисунок 2 - Объем экспорта высокотехнологичной продукции в 2012-2016 гг. (млн. дол. США)

Источник: [3]

Таким образом, на данном этапе развитие инновационной системы не создается необходимых предпосылок для производства передовых мировых технологий и повышения конкурентоспособности российских высокотехнологичных товаров. Можно отметить более низкий, по сравнению с другими странами, уровень финансирования научных исследований и разработок, а также недостаточное развитие инфраструктуры.

\section{ВЫВОДЫ}

Промышленная политика России в 2000-х гг. была направлена прежде всего на то, чтобы избежать негативных структурных изменений и компенсировать потери отечественных производителей. Направление этой политики в значительной степени определялось попытками использовать советский научно-технический потенциал. Только недавно стали появляться признаки инициативной повестки: промышленная политика была переориентирована на поддержку прогрессивных изменений в структуре экономики, развитие новых секторов и распространение передовых навыков и знаний. Инновационная политика также была направлена в сторону более активного развития новых навыков и областей знаний.

Система приоритетов в области промышленной политики постоянно трансформируется: диапазон приоритетов расширился до такой степени, что они лишены своей главной роли в консолидации усилий государства и бизнеса по работе над определенными прорывными областями развития. Как правило, приоритеты выбираются и изменяются без широкого диалога между обществом, государством и бизнесом.

Реализация эффективной промышленной политики в России также затрудняется из-за низкого качества государственных институтов, отсутствия или неэффективных каналов обратной связи и смещения компетенций государственных чиновников от технократического профиля (секторального, науки и техники) в отношении преимущественно экономического (финансового, управленческого или институционального) фона. Кроме 
того, ограничения в установлении приоритетов из-за преобладания существующих групп интересов и неэффективных соглашений являются дополнительными препятствиями.

Российская промышленная политика традиционно выбирала распределение финансовых ресурсов [7], в то время как нормативные инструменты считались неэффективными. Основные направления промышленной политики стимулировали внутренний спрос (в том числе посредством государственных закупок) и устанавливали квоты и предпочтения для определенных групп производителей. Фактически не разработана система оценки результатов внутренней промышленной политики. Процедура оценки основывалась только на использовании непрозрачных правил, основанных на совокупных оценках потенциальных бенефициаров. В этих условиях выявление и распространение передового опыта сведено к минимуму.

Проблема правильной оценки научно-технического потенциала и областей, где этот потенциал может быть использован, имеет большое значение для внедрения технологической промышленной политики. Многочисленные оценки кажутся завышенными, поскольку они основаны на идеях 20-30 лет, в частности в отношении структуры спроса на технологии в бизнесе и экономике в целом. Зависимость от наследия прошлых десятилетий иногда политически мотивирована и часто блокирует новые подходы и развитие международного технологического сотрудничества.

\section{СПИСОК ИСПОЛЬЗОВАННЫХ ИСТОНИКОВ}

1. Промышленная политика ЕАЭС: от создания к первым результатам. - Под редакцией С. С. Сидорского. - Москва 2015.

2. Кузнецов, Б. Нужна ли России промышленная политика? Б. Кузнецов // [Электронный ресурс]. - Режим доступа: http://www.kisi.kz/Parts/Monitoring/12.2001/1912mon2.html. - Дата доступа: 01.04.2018.

3. Статистическая база России [Элетронный ресурс]. - Режим доступа: http://www.gks.ru/. - Дата доступа: 03.04.2018.

4. Research and development expenditure [Electronic resource] // The World Bank. Mode of access: https://data.worldbank.org/indicator/GB.XPD.RSDV.GD.ZS. - Date of access: 06.04.2018.

5. Авдашева, С., Шаститко, А. Промышленная и конкурентная политика: проблемы взаимодействия и уроки для России / С. Авдашева, А. Шаститко // Вопросы экономики. - 2003. - № 9.

6. List of product imported by Russian Federation [Electronoic resource] // Trade Map. - Mode of access: http://trademap.org/Product_SelCountry_TS.aspx?nvpm=1|643||| TOTAL ||2|1|1|1|2|1|1|1|1. - Date of access: 08.04.2018.

7. Концепция долгосрочного социально-экономического развития Российской Федерации на период до 2020 года. Утверждена Распоряжением Правительства РФ от 17 ноября 2008 г. № 1662-р [Электронный ресурс] // Интернет-портал Правительства РФ. - Режим доступа: http://www.government.ru. - Дата доступа: 12.04.2018.

\section{REFERENCES}

1. Promyshlennaya politika EAEHS: ot sozdaniya $\mathrm{k}$ pervym rezul'tatam. Pod redakciej S. S. Sidorskogo. - Moskva 2015.

2. Kuznecov, B. Nuzhna li Rossii promyshlennaya politika? B. Kuznecov // [Ehlektronnyj resurs]. - Rezhim dostupa: http://www.kisi.kz/Parts/Monitoring/12.2001/19-12mon2.html. Data dostupa: 01.04.2018. 
3. Statisticheskaya baza Rossii [Ehletronnyj resurs]. - Rezhim dostupa: http://www.gks.ru/. - Data dostupa: 03.04.2018.

4. Research and development expenditure [Ehlektronnyj resurs] // The World Bank. Rezhim dostupa: https://data.worldbank.org/indicator/GB.XPD.RSDV.GD.ZS. - Data dostupa: 06.04.2018.

5. Avdasheva, S., SHastitko, A. Promyshlennaya i konkurentnaya politika: problemy vzaimodejstviya i uroki dlya Rossii / S. Avdasheva, A. Shastitko // Voprosy ehkonomiki. 2003. - № 9.

6. List of product imported by Russian Federation [Ehlektronnyj resurs] // Trade Map. - Rezhim dostupa: http://trademap.org/Product_SelCountry_TS.aspx?nvpm=1|643|||| TOTAL|||2|1|1|1|2|1|1|1|1. - Data dostupa: 08.04.2018.

7. Koncepciya dolgosrochnogo social'no-ehkonomicheskogo razvitiya Rossijskoj Federacii na period do 2020 goda. Utverzhdena Rasporyazheniem Pravitel'stva RF ot 17 noyabrya 2008 g. № 1662-r [EHlektronnyj resurs] // Internet-portal Pravitel'stva RF. - Rezhim dostupa: http://www.government.ru. - Data dostupa: 12.04.2018.

Статья поступила в редакциию 24 апреля 2018 года. 